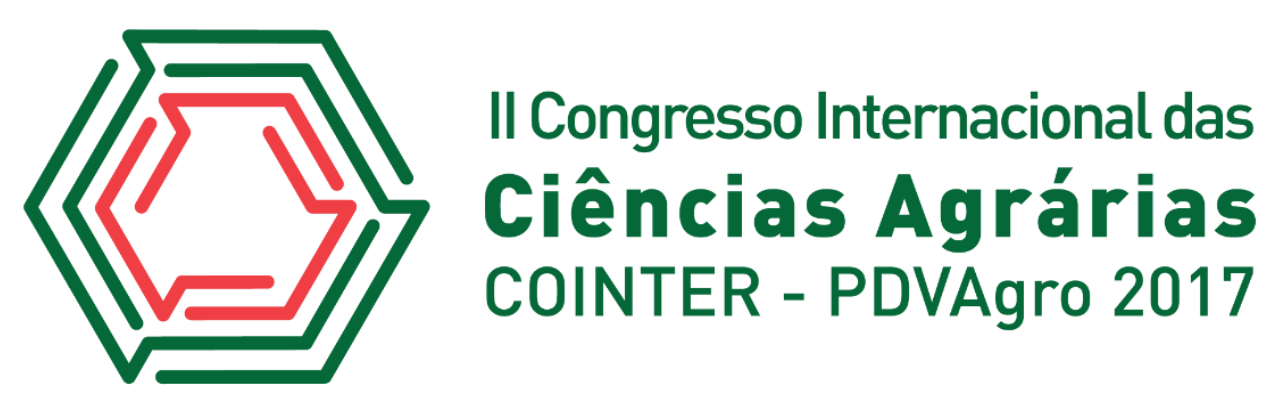

\title{
AVALIAÇÃO DOS PARÂMETROS DE COR NA CARNE DE FRANGO CONSERVADA COM ERVA-SAL (Atriplex nummulária)
}

\author{
Apresentação: Pôster
}

\begin{abstract}
Leandro Alves da Silva ${ }^{1}$; Laís Aryel Andrade de Oliveira ${ }^{2}$; Lucas de Oliveira Soares Rebouças $^{3}$; Vitor Lucas de Lima Melo ${ }^{4}$; Patrícia Lima de Oliveira ${ }^{5}$
\end{abstract}

\section{Introdução}

A produção de frangos de corte adota critérios importantes de produtividade, como rendimento de carcaça, produção de carne de peito e de pernas e qualidade da carcaça e da carne, o grau de importância dessas características varia de acordo com a empresa, o tipo de produto comercializado e o mercado ao qual se destina (MADEIRA, 2010). A garantia de manutenção do mercado de carne de frango, consiste no fornecimento de produtos com padrões de qualidade estáveis, visando à satisfação e segurança do consumidor, além de manter o poder aquisitivo (MULLER, 2012).

Para que se mantenha satisfatória a qualidade sensorial do produto cárneo (cor, textura, suculência, sabor, odor, maciez), tem-se utilizado conservantes naturais em substituição aos químicos para conservação de tais características. Nesse contexto, objetivou-se avaliar a adição de erva-sal na carne de frango e sua influência sobre a cor do produto in natura.

\section{Fundamentação Teórica}

Desde a origem do homem a carne faz parte de sua alimentação. "A explosão demográfica, aliada aos efeitos da urbanização, a mudança dos hábitos alimentares e o aumento gradual da renda nos países em desenvolvimento estão provocando uma elevação substancial no consumo de

\footnotetext{
${ }^{1}$ Zootecnia, Universidade Federal Rural do Semi-Árido (UFERSA), e-mail: leandrozotecnia@hotmail.com

2 Zootecnia, UFERSA, e-mail: aryel.lais@hotmail.com

${ }^{3}$ Pós Graduação em Ciência Animal, UFERSA, E-mail: lucaslosr@gmail.com

${ }^{4}$ Zootecnia, UFERSA; E-mail: vitor IIm@hotmail.com

${ }^{5}$ Docente da Universidade Federal Rural do Semi-Árido, UFERSA, e-mail: pattlima@ufersa.edu.br
} 
alimentos de origem animal" (BARBOSA, 2008).

A avicultura no Brasil foi uma das áreas de maior desenvolvimento nas últimas décadas e seu progresso não se ateve apenas por números de frangos abatidos ou no número de ovos produzidos, mas, sim, no caráter social da produção avícola, isto é, proteína de qualidade e baixo custo (MACARI; LUQUETTI, 2002).

Segundo Santos (2011), os padrões de qualidade, no que diz respeito à satisfação das exigências sensoriais, frequentemente apresentam variações indesejáveis nos parâmetros de cor e de maciez. A importância dessas características é observada em momentos distintos (BRESSAN; BERAQUET, 2002).

Dentre os parâmetros sensoriais, a cor da carne é o mais importante atributo de qualidade que influencia na aceitabilidade de produtos cárneos pelo consumidor, sendo, portanto, fator decisivo no momento da compra (PIZATO, 2011).

A cor da carne é largamente determinada pelos estados químicos e físicos do pigmento mioglobina do músculo que existe sob várias condições de estocagem, ou são produzidos pela cura e/ou aquecimento do produto, ou como um resultado de atividades microbianas (GILL et al., 2011).

\section{Metodologia}

O frango in natura foi adquirido em um supermercado local da cidade do Rio Grande do Norte - RN, o experimento foi realizado no Laboratório de Análises Instrumentais e Sensoriais (LANIS). As amostras foram cortadas e submetidas a diferentes tratamentos com erva-sal (ES): 0ES (controle), 1ES (1\% de adição da erva-sal); 2,5ES (2,5\% de adição da erva-sal); 5ES (5\% de ervasal).

As análises foram realizadas em triplicata, no seguinte período de armazenamento: zero, 24 horas após a inserção da erva-sal, e novamente após 3, 6, 9, 12 dias de armazenamento das amostras. A cor das amostras foi avaliada utilizando um colorímetro Konica Minolta, modelo CM700d/600d (sistema CIE L* $\mathrm{a}^{*} \mathrm{~b}^{*}$ ), cujo sistema considera as coordenadas $\mathrm{L}^{*}$ luminosidade (preto/branco), a* teor de vermelho (verde/vermelho) e $\mathrm{b}^{*}$ teor de amarelo-azul/amarelo (ABULARACH.; ROCHA; FELÍCIO, 1998).

As leituras foram feitas para 3 amostras da carne para cada tratamento e assim determinar os parâmetros de cor. A análise dos resultados, foram submetidos ao teste de comparação de médias 
pelo método de Tukey $(\mathrm{p}<0,05)$, utilizando o programa estatístico SISVAR versão 5.6.

\section{Resultados e Discussões}

Os valores das análises da cor das amostras estão dispostos na Tabela 1. De acordo com a análise de variância, a amostra controle (0ES) apresentou maiores valores de $\mathrm{L}^{*}$, diferindo significativamente dos demais tratamentos, esse resultado é indicativo de uma carne mais pálida. Em consequência de uma maior adição de erva-sal, o tratamento 5ES (5\% de erva-sal) teve um decréscimo mais expressivo em relação a esse atributo, sendo indicativo de uma amostra mais escura, provavelmente ocorrida pela coloração escura da erva-sal, consequentemente diminuindo a atratividade do consumidor em relação ao produto.

Tabela 1: Média e coeficiente de valores de luminosidade $\left(\mathrm{L}^{*}\right)$, teores de vermelho $\left(\mathrm{a}^{*}\right)$ e de amarelo $\left(\mathrm{b}^{*}\right)$ da carne do peito de frango. Fonte: Própria.

\begin{tabular}{|c|c|c|c|c|c|c|}
\hline \multirow{2}{*}{$\begin{array}{c}\text { Dias de } \\
\text { armazenamento }\end{array}$} & \multirow{2}{*}{ Variáveis } & \multicolumn{4}{|c|}{ Concentrações de erva sal } & \multirow{2}{*}{ CV\% } \\
\hline & & $0 \%$ & $1 \%$ & $2,5 \%$ & $5 \%$ & \\
\hline 0 & \multirow{6}{*}{$\mathrm{L}^{*}$} & $52,34 \mathrm{Aa}$ & $45,48 \mathrm{Ab}$ & $41,89 \mathrm{Ac}$ & $41,37 \mathrm{Ac}$ & \multirow{6}{*}{3,72} \\
\hline 1 & & $55,67 \mathrm{Aa}$ & $44,01 \mathrm{Ab}$ & $40,86 \mathrm{Abc}$ & $37,33 \mathrm{Ac}$ & \\
\hline 3 & & $45,23 \mathrm{Ba}$ & 47,95 $\mathrm{Aa}$ & $41,40 \mathrm{Ab}$ & $38,05 \mathrm{Ab}$ & \\
\hline 6 & & $51,63 \mathrm{Aa}$ & $44,17 \mathrm{Ab}$ & $40,75 \mathrm{Ac}$ & $37,10 \mathrm{Ac}$ & \\
\hline 9 & & $51,29 \mathrm{Aa}$ & $42,50 \mathrm{Ab}$ & $42,33 \mathrm{Ab}$ & $39,75 \mathrm{Ab}$ & \\
\hline 12 & & $51,63 \mathrm{Aa}$ & $44,17 \mathrm{Ab}$ & $40,75 \mathrm{Ab}$ & $37,10 \mathrm{Ac}$ & \\
\hline 0 & \multirow{6}{*}{$a^{*}$} & $-1,28 \mathrm{Bc}$ & $0,10 \mathrm{Bb}$ & $0,23 \mathrm{Bb}$ & 1,92 Aa & \multirow{6}{*}{15,67} \\
\hline 1 & & $-1,04 \mathrm{Bc}$ & $0,33 \mathrm{Bb}$ & $0,67 \mathrm{ABb}$ & $1,18 \mathrm{Aa}$ & \\
\hline 3 & & $-0,44 \mathrm{Ac}$ & $-0,09 \mathrm{Bbc}$ & $0,24 \mathrm{Bb}$ & $1,47 \mathrm{Aa}$ & \\
\hline 6 & & $-0,38 \mathrm{Ab}$ & $0,12 \mathrm{Bb}$ & $1,28 \mathrm{Aa}$ & 1,62 Aa & \\
\hline 9 & & $-0,29 \mathrm{Ac}$ & $0,15 \mathrm{Bb}$ & $0,62 \mathrm{ABb}$ & $1,71 \mathrm{Aa}$ & \\
\hline 12 & & $0,38 \mathrm{Ab}$ & 1,12 Aa & $1,28 \mathrm{Aa}$ & 1,62 Aa & \\
\hline 0 & \multirow{6}{*}{$b^{*}$} & $11,10 \mathrm{Ac}$ & $17,60 \mathrm{Ab}$ & 19,93 Aa & $22,09 \mathrm{Aa}$ & \multirow{6}{*}{11,22} \\
\hline 1 & & $12,17 \mathrm{Ac}$ & $17,20 \mathrm{Aab}$ & $18,26 \mathrm{Aa}$ & $20,53 \mathrm{Aa}$ & \\
\hline 3 & & 7,69 Bc & $15,66 \mathrm{Ab}$ & $18,45 \mathrm{Aa}$ & $19,93 \mathrm{Aa}$ & \\
\hline 6 & & $9,30 \mathrm{Bb}$ & 17,63 Aa & 19,80 Aa & $21,22 \mathrm{Aa}$ & \\
\hline 9 & & $5,74 \mathrm{Bc}$ & $15,79 \mathrm{Ab}$ & $16,75 \mathrm{ABb}$ & $23,11 \mathrm{Aa}$ & \\
\hline 12 & & $4,67 \mathrm{Bc}$ & $13,22 \mathrm{Ab}$ & $14,56 \mathrm{Bb}$ & $20,86 \mathrm{Aa}$ & \\
\hline
\end{tabular}

A,B Letras maiúsculas distintas na coluna indicam diferença entre os tratamentos pelo teste Tukey $5 \%$.

a, b, ${ }^{c}$ Letras minúsculas distintas na linha indicam diferença entre os tempos de armazenamento pelo teste Tukey $5 \%$ 
Corroborando com o presente estudo, Gok e Bor (2012) utilizando extrato de folhas de oliva e extrato de blueberry em almôndegas de frango por um período de 10 dias observaram que os valores de $\mathrm{L}^{*}$ reduziram com os dias amostrais. Segundo Komiyama (2006), em seus estudos acerca de caracterização da carne pálida em frangos de corte, relatou que filés de coloração normal apresentaram média em torno de 47,25.

A adição de erva-sal (Atriplex nummularia) atribuiu significativamente na cor da carne, aumentando os valores de $\mathrm{a}^{*}$ e $\mathrm{b}^{*}$. Os maiores valores de $\mathrm{a}^{*}$ e de $\mathrm{b}^{*}$ foram encontrados no nível 5ES em relação aos dias amostrais. No geral, os teores de $a^{*}$ aumentaram tanto com o aumento da concentração da erva-sal quanto aos dias amostrais, e os teores de $b^{*}$ também aumentaram com o aumento da concentração da ES, entretanto apresentou diferença significativa ( $<<5 \%$ ), em relação ao controle, a partir do $3^{\circ}$ dia amostral. Possivelmente esses resultados foram consequência de uma maior CRA.

Esses valores de a* estão em desacordo com os resultados encontrados por Santana (2015) quando adicionou o pó de cebola em almôndegas de frango, na qual em seu experimento encontrou diferença estatística apenas no nível de $0,05 \%$ de pó de cebola no $8^{\circ}$ dia amostral. Os valores médios da cor vermelha ( $\left.\mathrm{a}^{*}\right)$ de almôndegas com extrato de oliva e blueberry no estudo de Gok e Bor (2012) diminuíram com o aumento do tempo de estocagem, discordando também com a presente pesquisa.

Kim et al. (2014) e Santana (2015) também encontraram valores discordantes com o presente estudo para o atributo $b^{*}$, onde houve redução dos valores médios de $b^{*}$ com o aumento da concentração do pó de cebola.

\section{Conclusões}

De acordo com os resultados obtidos, conclui-se que a adição da erva-sal obteve resultado positivo para os parâmetros de cor nos 3 primeiros dias de conservação.

\section{Referências}

BARBOSA, S. B. P. Zootecnia: a ciência do novo século. Recife, PE, 2008.

BRESSAN, M. C.; BERAQUET, N. J. Efeito de fatores pré-abate sobre a qualidade da carne de peito de frango. Ciência e Agrotecnologia, v. 26, n. 5, p.1049-1059, 2002. 
MACARI, M.; LUQUETTI, C. B.; Fisiologia cardiovascular. In: MACARI, M.; FURLAN, R.L.; GONZALES, E.; Fisiologia aviária aplicada a frangos de corte. Jaboticabal, SP: FUNEP, 2002. p. 17-35.

GILL, C. O., HOLLEY, R. A. Mecanismos de mudanças de cor em carnes frescas e processadas. 2011.

GOK,V., BOR,Y. Effect of olive leaf, blueberry and zizyphus jujuba etracts on the quality and shelf life of meatball during storage. Journal of Food, Agriculture and Environment. Helsinki,v.10, n.2, p. 190-195, 2012.

KIM,H.J. et. al. Improvement of microbiological safety and sensorial quality of pork jerky by electron beam irradiation and by addition of onion peel extract and barbecue flavor. Radiation Physics and Chemistry, elbourne, v.28, n.1, p. 22-28, 2014.

KOMIYAMA, C.M. Caracterização e ocorrência de carne pálida em frangos de corte e seu efeito na elaboração de produtos industrializados. 2006. 89f. Dissertação (Mestrado em Zootecnia) - Curso de Pós-graduação em Zootecnia, Faculdade de Medicina Veterinária e Zootecnia, Universidade Estadual Paulista, Botucatu, SP.

MADEIRA, L.A. et al. Avaliação do desempenho e do rendimento de carcaça de quatro linhagens de frangos de corte em dois sistemas de criação. Revista Brasileira de Zootecnia. v.39, n.10, Viçosa, out. 2010.

MULLER, A.T.; PASCHOAL, E.C.; SANTOS, J.M.G. Impacto do manejo pré-abate na qualidade da carne de frango. Revista em Agronegócios e Meio Ambiente, v.5, n.1, p. 61-80, jan. /abr. 2012.

PIZATO, S. et al. Avaliação de cor e textura de filés de frango in natura embalados em atmosfera modificada gasosa. In: Embrapa Suínos e Aves-Artigo em anais de congresso (ALICE). In: CONGRESSO BRASILEIRO DE CIÊNCIA E TECNOLOGIA DE CARNES, 6., 2011, São Pedro, SP. Anais... São Pedro, SP: ITAL/CTC, 2011. p. 1-3.

SANTANA, A.T.M.C. Resíduo de cebola (Allium cepa L.) como conservante natural em carne. Dissertação (mestrado), Escola Superior de Agricultura Luiz de Queiroz, Piracicaba,2015. 